\title{
A NOVA CONFIGURAÇÃO DO TRABALHO DOCENTE NA EDUCAÇÃO SUPERIOR: o caso do curso de Pedagogia/UFJF da Universidade Aberta do Brasil1
}

Mariana Novais Vieira²

\begin{abstract}
Resumo
Este artigo tem como objetivo analisar a configuração do trabalho docente no âmbito da política de expansão de educação superior, por meio da Educação a Distância (EaD), com a institucionalização do Sistema Universidade Aberta do Brasil (UAB). A política de expansão do ensino superior a partir da UAB, baseado nos pressupostos do modelo de Estado gerencial, vem redefinindo a configuração do trabalho do professor por meio da intensificação e precarização de seu trabalho, revelando que a opção ideológica do bloco no poder em assegurar o direito de acesso à educação superior se processa pelo comprometimento das condições de trabalho/vida dos trabalhadores docentes.
\end{abstract}

Palavras-chaves: Trabalho docente - Universidade Aberta do Brasil Intensificação do trabalho.

\begin{abstract}
This article aims to analyze the configuration of the teaching work in the context of the policy of expansion of higher education, through distance education (EaD), with the institutionalization of the Open University of Brazil (UAB) system. The policy of expansion of higher education at the UAB, based on the state management assumptions, has been redefining the teacher's work layout through the intensification and precariousness of their work, revealing that the ideological choice of the bloc in power to ensure the right of access to higher education is processed by the commitment of the teachers' conditions of life and work.
\end{abstract}

Keywords: Teaching - Open University of Brazil - Work intensification.

\footnotetext{
${ }^{1}$ DOI: https://doi.org/10.22409/tn.15i26.p9626

2 Doutoranda em Educação pela Universidade Federal de Minas Gerais; Mestre em Educação pela Universidade Federal de Juiz de Fora; Professora da Educação Básica da Rede Municipal de Juiz de Fora. E-mail: marijf_2006@hotmail.com
}

TrabalhoNecessario - www.uff.br/trabalhonecessario; Ano 15, № 26/2017 


\section{Introdução}

As reflexões presentes neste artigo foram desenvolvidas em uma pesquisa $^{2}$ do Curso de Mestrado do Programa de Pós-Graduação em Educação da Universidade Federal de Juiz de Fora (UFJF), defendida no ano de 2013, sob orientação do professor André Silva Martins. A pesquisa em questão buscou analisar o trabalho docente no contexto da política de expansão do ensino superior, por meio da Educação a Distância (EaD), com a institucionalização do Sistema Universidade Aberta do Brasil (UAB). Com o intuito de dar continuidade ao estudo relacionado ao trabalho docente na $\mathrm{EaD}$, atualmente realizo o Curso de Doutorado do Programa de Pós-Graduação em Educação da Universidade Federal de Minas Gerais (UFMG), cuja pesquisa pretende analisar criticamente o trabalho do tutor nos cursos de graduação a distância das universidades públicas federais.

A opção teórico-metodológica adotada é pelo materialismo histórico. Não se trata de uma escolha arbitrária, ao contrário, essa opção é sustentada na compreensão de que os fundamentos do método materialista histórico permitem ao pesquisador: (i) construir o conhecimento a partir de uma prática social, já que toda teoria do conhecimento se apóia sobre uma determinada realidade; (ii) apreender os dados da realidade como sínteses de múltiplas determinações, considerando os fenômenos sociais para além de suas manifestações imediatas ou aparentes.

Reconhece-se que o materialismo histórico não é um método de redução da realidade, mas sim de reprodução da realidade no plano teórico, por meio de diferentes mediações realizadas pela atividade humana com auxílio de categorias de análises, que emergem da dinâmica do mundo real. Esse método permite compreender as manifestações sociais (políticas, econômicas, educacionais, etc.) como atividade prática e objetiva dos homens e mulheres reais organizados em um tempo histórico e em uma sociedade (KOSIK, 1976).

A pesquisa buscou responder às seguintes questões: a UAB, como parte da política de ampliação do acesso ao ensino superior e de formação de professores, produziu algum tipo de mudança na configuração e na dinâmica do trabalho docente na universidade pública? No contexto da UAB, o trabalho

\footnotetext{
${ }^{2}$ Dissertação disponível em: <http://www.ufff.br/ppge/files/2013/09/Disserta\%C3\%A7\%C3\%A3oFinal.pdf> Acesso em: 07 fev. 2017.
} 
docente se desenvolve de forma precarizada e/ou intensificada?

Com base nessas indagações, o objetivo geral da pesquisa foi analisar a configuração do trabalho docente no contexto da política de expansão e consolidação da educação superior no âmbito da UAB, tendo em vista as relações sociais que delineiam a realidade concreta e a política educacional de modo específico. Como objetivos específicos, buscou-se analisar o trabalho docente no curso de Pedagogia da UAB/UFJF, a partir da figura do professor, de forma a apreender: (i) a natureza e a dinâmica do trabalho do professor nessa modalidade de ensino; (ii) as condições de trabalho desses sujeitos; (iii) o significado político do trabalho do professor para a política da UAB.

Para tanto, foram utilizadas as seguintes técnicas de investigação: (i) estudo teórico, de caráter descritivo-analítico, para traçar a base de compreensão sobre o trabalho e a educação nas relações sociais capitalistas e apreender estratégias de controle sobre o trabalho, de forma geral, e o trabalho docente, de forma específica; (ii) estudo documental da política de educação implementada nos anos de 1990 e 2000 no âmbito federal, tendo a educação superior como base; (iii) análise de dados obtidos através de questionários aplicados junto aos professores do curso de Pedagogia/UAB da UFJF, considerando os aspectos teóricos e organizativos sobre EaD e trabalho docente, no conjunto das relações societais e das políticas educacionais.

A fim de analisar a configuração do trabalho docente na educação superior, com a institucionalização da $U A B$, torna-se necessário definir alguns conceitos teóricos referentes à sociedade capitalista, a partir do pensamento de Gramsci e Poulantzas. Para tanto, o caminho teórico-metodológico percorrido viabilizou abordar conceitos a respeito do Estado, buscando uma compreensão crítica da realidade, assim como a apreensão do fenômeno em estudo no conjunto das relações sociais, permeada por contradições.

Nessa perspectiva, o Estado na sociedade capitalista não se limita à aparelhagem estatal (Executivo, Legislativo e Judiciário), é uma complexa construção social formada pelo bloco histórico, que se refere à unidade do diverso e do contraditório, no qual há indissociabilidade dos fenômenos sociais a partir da relação dialética entre estrutura (nível concreto do mundo, que envolve a produção das condições da existência) e superestrutura (nível simbólico, que envolve valores, ideias, comportamentos). Nas palavras de Gramsci (2011), bloco 
histórico é a "[...] unidade entre a natureza e o espírito (estrutura e superestrutura), unidade dos contrários e dos distintos" (GRAMSCl, 2011, p.26).

Nessa linha de pensamento e de acordo com Poulantzas (2000), o Estado deixa de ser interpretado como instrumento passivo e neutro (Estado como coisa), bem como superior, com racionalidade própria, apartado das relações sociais (Estado como sujeito), para ser compreendido como resultante das relações sociais estabelecidas entre classes e frações de classe, em que os diferentes interesses são incorporados sob uma determinada classe ou fração, subordinando as demais nesse processo (Estado como relação).

A constituição relacional do Estado conduz a outro conceito importante, referente ao bloco no poder. Esse constructo possibilita compreender a unidade e a diversidade de interesses de classes, presentes numa aliança política, assumidas pelas instâncias de exercício de poder no aparelho de Estado, na forma de governo. O conceito de bloco no poder permite revelar como as frações de classe se organizam nas instâncias da aparelhagem estatal e como os interesses distintos ou mesmos contraditórios entram em relação no interior dos governos e suas repercussões nas funções do Estado (POULANTZAS, 2000).

Com isso, o Estado atua como educador a partir dos resultados dos processos de hegemonia (GRAMSCI, 2011). As relações de classe estabelecidas, e que dão vida ao Estado, transformam-se em relações educativas e se materializam nas políticas sociais, nas políticas econômicas e nas diferentes práticas culturais. Assim, "[...] a função do Estado educador é organizar a sociabilidade capitalista e, ao mesmo tempo, desestruturar e assimilar de modo subordinado as outras formas de sociabilidade existentes nos espaços sociais" (MARTINS, 2011, p.81).

Segundo Gramsci (2011), '[...] por 'Estado' deve-se entender, além do aparelho de governo, também o aparelho 'privado' de hegemonia ou sociedade civil" (GRAMSCI, 2011, p.254-255). Nessa concepção, o Estado passa a ser Estado ampliado, sendo formado pela aparelhagem estatal e pela sociedade civil. Enquanto a primeira corresponde à instância de disputas e coerção, para manter o consenso, a segunda refere-se aos aparelhos privados de hegemonia e ao espaço da luta de classes e de projetos societários antagônicos. Na ampliação do Estado, ao conceber a aparelhagem estatal como instância da luta de classes, há um reconhecimento por parte da burguesia da classe trabalhadora enquanto

TrabalhoNecessario - www.uff.br/trabalhonecessario; Ano 15, № 26/2017 
classe, a fim de que o consenso seja mantido.

Os conceitos teóricos aqui apresentados - bloco histórico, bloco no poder, Estado relacional, Estado educador, Estado ampliado - são fundamentais para compreender as relações estabelecidas na sociedade capitalista, uma vez que proporcionam uma explicação crítica do significado das políticas sociais, dentre elas a educação, no contexto da produção e reprodução das relações sociais no capitalismo, possibilitando ir além das manifestações imediatas do fenômeno social estudado, desvendando suas contradições e apreendendo os dados da realidade como sínteses de múltiplas determinações.

Além desses conceitos, acrescenta-se outro de grande importância. Tratase do conceito de trabalho. Para delimitá-lo, será trabalhado com Marx e a partir de Marx.

Ao longo da história, as mudanças políticas e econômicas ocorridas na sociedade trouxeram implicações para a configuração do trabalho. O trabalho é diversificado e alterado no seu conteúdo histórico: as produções que dependiam exclusivamente do trabalho manual passaram a ser feitas por meio de máquinas; os atos de planejar e executar foram cindidos, novas exigências comportamentais e intelectuais foram definidas.

É preciso considerar que o trabalho é condição básica para a vida humana e é através dele que o ser torna-se social. Com o trabalho o homem exerce influência sobre a natureza de modo intencional e planejado, o que o diferencia dos demais animais (ENGELS, 1876).

$\mathrm{Na}$ sociedade capitalista, o processo de trabalho torna-se um meio de subsistência e a força de trabalho, uma mercadoria. Isso faz com que o trabalho torne-se um meio e não uma necessidade fundamental de realização humana. $O$ resultado disso é expresso no estranhamento e, também, na alienação do trabalhador, o que inibe a realização da ominilaterialidade humana, ou seja, o desenvolvimento do ser na sua totalidade, na sua integridade. Para Antunes (1997), há uma tendência geral no capitalismo pela forma como o trabalho se realiza: "[...] o trabalhador repudia o trabalho; não se satisfaz, mas se degrada; não se reconhece, mas se nega" (ANTUNES, 1997, p.125).

Nesse sentido, ao mesmo tempo em que o trabalho é considerado a condição básica para a vida humana, também promove a alienação humana, sendo, portanto, uma unidade contraditória.

TrabalhoNecessario - www.uff.br/trabalhonecessario; Ano 15, №26/2017 
Isso significa ultrapassar a noção de trabalho no capitalismo concentrado como pura negatividade ou como pura positividade. Dessa forma, o trabalho passa a ser compreendido como uma unidade contraditória indivisível entre positividade e negatividade, já que produz tanto a libertação do ser humano da sua condição animalesca (positividade), transformando-o em ser social; quanto produz sua degradação (negatividade), por meio da alienação.

De acordo com Marx (1983), o processo de trabalho é uma atividade orientada para produzir valores de uso que se convertem em valores de troca. $\mathrm{O}$ valor de uso é aquilo que resulta do trabalho para satisfazer as necessidades humanas. Ao produzir valores de uso, o trabalho é considerado material. $\mathrm{Na}$ medida em que o resultado da força de trabalho ultrapassa o plano do atendimento das necessidades do trabalhador, assumindo a forma mercadoria, converte-se em valor de troca. Nas relações capitalistas, o processo de trabalho gera mais-valia, o que significa exploração, já que para se obter a mais-valia, prolonga-se a jornada de trabalho do trabalhador e não se paga por estas horas a mais trabalhadas, também chamada de "horas de sobretrabalho". Denomina-se "[...] mais-valia ou lucro, aquela parte do valor total da mercadoria em que se incorpora o sobretrabalho, ou trabalho não remunerado" (MARX, 1950, p.77).

No trabalho imaterial a questão é mais complexa, pois o resultado final não assume uma forma material, um valor de uso. Em outras palavras, o trabalho imaterial não se expressa no objeto físico que pode ser manipulado. Com isso, embora necessário para a reprodução ampliada do capital, o trabalho torna-se improdutivo, isto é, não produz imediatamente o valor de uso e nem valor de troca, sendo difícil precisar a geração de mais-valia.

Marx (1975), apud Bomfim (2008), distingue duas formas de sujeição do processo de trabalho no capitalismo: a subsunção real e a subsunção formal. A primeira refere-se ao que denominou de mais-valia absoluta, dada pelo prolongamento da jornada de trabalho; a segunda funda-se na mais-valia relativa, possibilitada pela revolução no modo de produzir e na produtividade, devido, principalmente, à aplicação da ciência e da maquinaria na produção.

É interessante ressaltar que a distinção entre trabalho produtivo e improdutivo é, somente, uma maneira de especificar o trabalho na dinâmica da sociedade capitalista. É a relação que se estabelece com o trabalho e não o conteúdo que o define como produtivo ou improdutivo. Nesse sentido, "trabalho

TrabalhoNecessario - www.uff.br/trabalhonecessario; Ano 15, № 26/2017 
produtivo não é senão expressão sucinta que designa a relação integral e o modo pelo qual se apresentam a força de trabalho e o trabalho no processo capitalistas de produção" (MARX, 1978, p.131)

Assim, um mesmo trabalho pode ser imaterial e produtivo e, também, imaterial e improdutivo, como é o caso do trabalho docente. O professor da rede privada exerce um trabalho produtivo, pois gera mais-valia para os proprietários dos estabelecimentos de ensino; mas este mesmo professor, atuando no setor público, exerce um trabalho improdutivo. Em ambas as formas o trabalho pode ser qualificado de imaterial.

O resultado final do trabalho docente, que é o ensino, não atinge uma forma definida ao final do processo, sendo, portanto, imaterial, pois seu valor de uso acontece ao longo do processo e não se transforma em valor de troca. O trabalho de ensinar refere-se à formação do homem, assim, "pelo trabalho, os professores ensinam outros seres humanos a produzir sua própria existência, visto que o ser humano não nasce pronto. Precisa, portanto, ser educado" (BOMFIM, 2010, p.89). O que é ensinado ao aluno passa a ter um valor indireto diante de outros tipos de trabalho material, isto é, o conhecimento ensinado pelo professor e apropriado pelo aluno não é algo que se aplica imediatamente, mas sim mediatamente no seu trabalho futuro.

Diante disso, pode-se considerar que apenas os trabalhadores produtivos, aqueles que produzem mais-valia, passam pelo processo de exploração do sistema capitalista?

Considera-se, assim como Frigotto (2009), que tanto os professores da rede pública, quanto os professores da rede privada - mesmo o primeiro exercendo um trabalho imaterial e improdutivo e o segundo, um trabalho imaterial e produtivo - são explorados. A diferença central está nas mediações em que se processa a exploração. Enquanto a exploração dos professores do setor privado é direta, seguindo a forma clássica, no caso dos professores do setor público, a exploração se faz pelas intermediações do aparelho de Estado e das políticas públicas, envolvendo o controle sobre o fundo público. A exploração dos professores do setor público significa, em geral, uma economia do fundo público, algo que passa a ser apropriado por diferentes meios pela classe empresarial.

No contexto capitalista, o trabalho improdutivo é submetido ao processo de exploração, mesmo que não haja extração direta da mais-valia, nada escapa a 
ordem do capital. Portanto, defende-se que, no processo histórico, mesmo o trabalhador assalariado do setor público, que não produz valor de troca, torna-se também um ser explorado e submetido aos mesmos princípios da exploração que envolve o trabalho concreto. Como resultado, esse trabalhador vive os efeitos dramáticos diretos/indiretos da exploração capitalista em sua especificidade.

Nesse sentido, os trabalhadores docentes, mesmo exercendo um trabalho imaterial, são trabalhadores assalariados, seja na rede pública ou na rede privada de ensino, e estão submetidos às leis gerais da exploração capitalista.

A relação contratual baseada no assalariamento é uma forma de relação de produção especificamente capitalista, independente se o trabalhador exerce ou não trabalho produtivo, seja vinculado às agências da aparelhagem estatal ou empresas de ensino. Marx (1978) defende que

[...] com o desenvolvimento da produção capitalista todos os serviços se transformaram em trabalho assalariado, e todos os seus executantes em assalariados, tendo, pois, essa característica em comum com o trabalhador produtivo, leva tanto mais à confusão entre uns e outros porquanto fenômeno característico da produção capitalista, e por ela gerado. (MARX, 1978, p.130)

Então, apesar dos trabalhadores docentes do setor público exercerem um trabalho improdutivo, também passam pelo processo de exploração, deixando de controlar o seu próprio trabalho. Isso significa que esses trabalhadores também sofrem o processo de exploração, pois aquilo que não se paga na forma salário transforma-se em processo de valorização do fundo público, geralmente servindo para financiar a valorização do capital em seu conjunto.

Desse modo, constata-se que as relações sociais capitalistas ao definirem a lógica de funcionamento da produção, definem, também, as relações de trabalho, levando-as, no contexto atual, a novas formas de exploração, precarização e intensificação, independente do trabalho ser produtivo ou improdutivo.

Estabelecida as delimitações conceituais mais significativas é possível delimitar a estrutura deste artigo. Além da introdução o artigo conta com mais três seções: "Estado Capitalista e Educação: elementos históricos e teóricos que antecedem a expansão da educação superior"; "A configuração do Sistema UAB 
no processo de expansão da educação superior"; e "A condição de trabalho docente na UAB: caso Pedagogia/UFJF”. E para finalizar, é apresentado as "Considerações Finais"

\section{Estado Capitalista e Educação: elementos históricos e teóricos que antecedem a expansão da educação superior}

O sistema capitalista de produção da existência humana, em função de sua constituição orgânica contraditória, demonstra ser um sistema que vive crises, mais ou menos intensas, devido à dinâmica das relações sociais e de poder constituídas em cada momento histórico nas diferentes formações sociais. As crises de 1929, 1970, 1997 e 2008 são exemplos da dinâmica desse sistema.

As crises têm uma mesma origem, com uma materialidade específica, "[...] a crise é um elemento constituinte, estrutural, do movimento cíclico da acumulação capitalista, assumindo formas específicas que variam de intensidade no tempo e no espaço" (FRIGOTTO, 2003, p.62). As medidas de superação das crises são processadas na dinâmica das relações sociais, envolvendo reorganização do processo produtivo em crise, mudanças nos procedimentos de gestão da força de trabalho e redefinição das relações de poder por meio de diferentes mecanismos políticos.

No século XX, uma das crises mais significativas foi a de 1929. Os efeitos dessa crise foram duradouros, impactando de forma incisiva na condição de vida e no modo de ser da classe trabalhadora. A superação temporária da crise de 1929 foi viabilizada por mudanças significativas na conduta política da classe burguesa. Em linhas gerais, as mudanças envolveram a redefinição das funções da aparelhagem estatal e suas agências nas questões econômicas e sociais. No quadro de crise, esse processo envolveu mecanismos de força para controle dos trabalhadores considerados "rebeldes"; processos de convencimento da sociedade para a nova dinâmica social, exercidas pelos aparelhos privados de hegemonia da classe empresarial; a adoção do planejamento macroeconômico como medida anticrise; o desenvolvimento de políticas sociais destinadas, de um lado, à reprodução ampliada da força de trabalho, de outro, a responder às demandas dos trabalhadores empobrecidos no contexto de desemprego. Tudo isso em nome da retomada do progresso e da coesão social. 
Essas medidas, iniciadas nos Estados Unidos a partir da reorganização das relações sociais, com repercussões importantes em países da Europa ocidental abalados pelos efeitos da guerra, resultaram na criação de um novo modelo de Estado - o chamado: Estado de Bem-Estar Social (Welfare State) -, que contou com políticas sociais para minimizar as desigualdades e viabilizar o consumo em massa da produção em grande escala.

Nesse modelo estatal, trabalhadores e empresários, sem alterar as posições no processo de dominação-exploração, estabeleceram um contraditório pacto social que propiciou, ao mesmo tempo, atender os interesses dos trabalhadores, fazendo com que a burguesia reconhecesse os direitos de cidadania política e social desses segmentos, e recuperar a hegemonia burguesa e o sistema capitalista. As políticas sociais possibilitam a elevação da condição civilizatória, no entanto, jamais superarão os elementos centrais do capitalismo de dominação e exploração.

No âmbito da sociedade civil, os trabalhadores redesenharam seus horizontes de luta e de contestação, admitindo, ainda que com divergências, a possibilidade histórica de um capitalismo de face humanizada. Os empresários, por sua vez, reconstruíram suas práticas políticas, aceitando o diálogo e passando a influenciar no padrão de sociabilidade por meio de mecanismos de novo tipo. O bloco no poder (invariavelmente hegemonizado por frações da burguesia com ou sem participação de frações da classe trabalhadora), nas formações capitalistas centrais, se empenhou em ordenar uma aparelhagem estatal forte e atuante nas questões econômicas e sociais, assegurando uma suposta harmonia entre capital-trabalho com base na ideologia do desenvolvimento e do progresso.

Em relação à educação, os desdobramentos do pacto social nos países centrais resultaram na afirmação de sistemas públicos de ensino rapidamente reestruturados e abrangentes, no que diz respeito ao acesso e à permanência, e um intenso debate sobre perspectivas pedagógicas, principalmente considerando a condição infantil no pós-guerra.

A partir do restabelecimento das relações de poder, a educação nesses países passou a ser disputada como um "direito social", mesmo que esse direito fosse atrelado, já nos anos de 1950, à teoria do capital humano, sob forte controle estatal nos marcos do esforço de reconstrução europeia dirigida pelos Estados

TrabalhoNecessario - www.uff.br/trabalhonecessario; Ano 15, № 26/2017 
Unidos (TEODORO, 2000).

Nesse contexto, a EaD também teve um crescimento significativo. Embora os primeiros registros sobre essa modalidade de ensino se manifestem no final do século XIX, com cursos por correspondências, foi em 1962 que iniciou a primeira experiência de ensino com tecnologia mais arrojada: rádio e televisão.

A proposta de Universidade Aberta (Open University) surgiu em 1965 com o Projeto AIM (Articulated Instructional Media Project) da University of Wisconsin, nos Estados Unidos, e "[...] constitui em avaliar a utilização de diferentes tecnologias de comunicação para oferecer ensino de alta qualidade com um custo reduzido" (TREIN; CHAGAS, 2009, p.4). O governo britânico, ao tomar conhecimento do Projeto AIM, propôs a discussão e criação de uma universidade, visto que o protótipo experimental do Projeto AIM apresentava falhas em relação ao corpo docente, currículo e recursos financeiros.

A partir desse modelo de Universidade Aberta, presencia-se a expansão da EaD em diversos países, evidenciando as preocupações do bloco no poder com a ampliação da formação da classe trabalhadora, tendo em vista a aceleração do ritmo de crescimento econômico. Acompanhando esse movimento, foram criadas também a Univesid Nacional de Educacion a Distancia na Espanha (1972) e a Fern Universität in Hagen na Alemanha (1975).

O bloco no poder, portanto, diferentemente do período anterior ao de 1929 , reordenou o Estado e as políticas públicas, assegurando uma intervenção direta em todos os temas sociais - especialmente na educação - e na economia a partir da nova correlação de forças restabelecidas nesses países.

Vale esclarecer que as experiências internacionais que viabilizaram o modelo de Estado de Bem-Estar Social nos países centrais não se materializaram do mesmo modo nos países periféricos. Na América Latina, especialmente, as relações de poder resultaram no Estado desenvolvimentista - um modelo baseado na forte intervenção estatal no desenvolvimento industrial, de urbanização e de infraestrutura para as atividades econômicas, com atendimento seletivo das demandas de frações urbanas sem, contudo, assegurar direitos sociais amplos. A função do Estado desenvolvimentista foi a de assegurar novas bases para a produção e acumulação privada da riqueza e de acomodação das tensões sociais, sem alterações nas relações de poder.

Nos anos de 1930, a política educacional brasileira foi definida como

TrabalhoNecessario - www.uff.br/trabalhonecessario; Ano 15, № 26/2017 
necessidade de preparação seletiva da força de trabalho para a nova fase de desenvolvimento político-econômico capitalista do país. Nesse processo, a educação se configurou como um dos mecanismos de reprodução ampliada da força de trabalho. Isso significou algum tipo de formação do cidadão-trabalhador para operar com uma racionalidade compatível com o trabalho fabril e com a vida social urbana.

A partir da segunda metade dos anos de 1970, nos países centrais, o padrão de desenvolvimento centrado num Estado com muitas funções econômicas e sociais, passou a ser questionado por setores da burguesia inconformados com a desaceleração do ritmo de crescimento econômico. Tais setores passaram a defender novas referências para ordenamento da aparelhagem estatal, tanto nas questões sociais quanto nas de ordem econômica. Defendiam a retomada de princípios liberais para orientar as sociedades capitalistas modernas, valorizando o mercado como centro da atividade vital, marcando, assim, o encerramento da "era de ouro do capital" (HOBSBAWN, 1995).

A diminuição no ritmo de crescimento econômico nos países capitalistas centrais e o nível de correlação de forças estabelecidas entre as classes sociais e suas frações, resultaram na vitória de forças políticas alinhadas ao ideário "neoliberal".

Com base em "novas" ideias sobre Estado, economia, política e educação, as forças burguesas, por meio de mecanismos de força e de consenso, foram estabelecendo referências importantes para reordenar as bases do padrão de sociabilidade. O pacto em torno do modelo de Estado de Bem-Estar Social foi rompido e com ele novas referências ganharam espaço, instruindo, não sem resistência, o novo papel das classes nas relações sociais e também o modo de ser de cada classe.

Nesse contexto de reconstituição do bloco histórico, o ideário neoliberal foi confirmado como a base ideológica do caminho alternativo de recuperação econômica e de edificação da nova sociabilidade. As referências desse projeto consideraram a suposta superioridade do mercado sobre o Estado como um fato; a necessidade de uma interferência mínima do Estado sobre as questões sociais - entre elas a educação - como um princípio; e o aumento da produtividade do trabalho como uma necessidade. Assim, derrubar o modelo de Estado de Bem- 
Estar Social e todo sistema por ele articulado seria um imperativo de primeira ordem.

Contudo, a proposta de Estado mínimo, defendido pelo neoliberalismo ortodoxo, mostrou seus limites, uma vez que seria pouco eficiente em relação às funções do aparelho de Estado e à organização da sociedade civil, o que levariam a problemas na coesão social e no ordenamento da sociabilidade, especificamente para a produtividade da força de trabalho (MARTINS, 2011).

Convém ressaltar que a difusão ideológica do neoliberalismo no Brasil se deu com o surgimento do Instituto Liberal (IL), nos anos de 1980. As atividades desses Institutos baseiam-se na divulgação da concepção de mundo neoliberal, assim como na doutrinação ideológica entre as elites brasileiras e na formulação de propostas de políticas públicas de caráter neoliberal, tendo na lógica empresarial a orientação para reforma do Estado. O responsável pela difusão dos principais aspectos do neoliberalismo no Brasil, em consonância com as diretrizes do Consenso do Washington, foi o bloco no poder instituído a partir dos anos de 1990.

As formulações do neoliberalismo e seu modelo de Estado mínino demonstraram ser insuficientes para atender as demandas políticas e econômicas dos anos de 1990. Para tanto, buscou-se a elaboração de um projeto político que seria um caminho alternativo entre os ideais da social-democracia clássica e as formulações do neoliberalismo ortodoxo, sendo este denominado de neoliberalismo da Terceira Via, no qual o aparelho de Estado incorpora o modelo gerencial de administração, configurando-se em Estado regulador, e a sociedade civil converte-se em espaço da colaboração social. Esse projeto foi sistematizado por Antonhy Giddens a partir dos pressupostos da atualização da agenda da social-democracia em nível mundial. Trata-se de um projeto que visa estabelecer um modelo capitalista de face mais humanizada.

A política neoliberal da Terceira Via é baseada numa nova dinâmica: atuação do governo em parceria com organizações de cunho econômico ou social a fim de fomentar a renovação do desenvolvimento. Trata-se de [...] uma nova sinergia entre os setores público e privado, utilizando o dinamismo dos mercados mas tendo em mente o interesse público. (GIDDENS, 2001, p.109-110)

Tanto para o programa neoliberal da Terceira Via quanto para 0 neoliberalismo ortodoxo, deve ser eliminada toda e qualquer política estatal que 
incentive a passividade dos indivíduos, que gere obstáculos para a expansão do mercado e que crie dificuldades para o pacto entre capital e trabalho. Assim, o Estado deve ter suas funções alteradas, ao invés de interventor ou ausente, deve se configurar como regulador da economia e da dinâmica social por ser o centro legítimo de poder, assumindo um modelo gerencial.

Uma das características do Estado segundo o modelo gerencial, nos termos propostos pela Terceira Via, é o incentivo à incorporação das Tecnologias da Informação e da Comunicação (TIC) na vida social, tanto naquilo que envolve as políticas públicas quanto no que se relaciona aos processos sociais mais gerais.

A defesa de novos modelos tecnológicos e organizacionais, possibilitado pelas TIC, são concebidos como referências para o aumento da eficiência e aumento da produtividade. A ideia de flexibilidade presente nas TIC permite a racionalização do trabalho, a diminuição dos custos e o controle de tipo "não burocrático", princípio político que deve abranger todos os assuntos e temas públicos, segundo esse modelo estatal.

Mais do que um processo natural, o avanço das TIC no campo educacional, principalmente com a difusão da modalidade da EaD, é resultado de uma concepção de Estado e de uma forma de funcionamento da política educacional defendida pelo bloco no poder, independentemente das implicações negativas sobre os processos de trabalho e de formação humana que isso possa causar. Para os defensores do modelo de Estado gerencial, a utilização de tecnologias representa o aumento da produtividade e a racionalização dos gastos, com bons resultados finais.

As reformas educacionais brasileiras ocorridas ao longo dos governos, a partir dos anos de 1990, responderam às novas demandas do mercado de trabalho, estando em conformidade com a política de acumulação flexível e com as políticas das agências financeiras internacionais. Isso gerou consequências para o trabalho docente em todos os níveis de ensino, em especial para o ensino superior, diante da política de expansão desse nível de ensino por meio da EaD.

No que se refere ao avanço da modalidade a distância, mediada pelas TIC, faz-se necessário analisar até que ponto a inserção das TIC no campo educacional, interfere no processo de trabalho docente. A EaD na educação superior brasileira, consolidou-se com institucionalização do Sistema UAB,

TrabalhoNecessario - www.uff.br/trabalhonecessario; Ano 15, №26/2017 
dirigida à formação de professores.

Com a UAB, um novo quadro político delineia-se, já que foram estabelecidas novas regulamentações de funcionamento dos cursos; criou-se novas funções no processo de ensino e aprendizagem, assim como novas relações de trabalho e institucionais; e instituiu-se diferenciações salariais, devido à distribuição de bolsas para os professores participantes do programa (OSÓRIO; GARCIA, 2011).

A EaD passou a ocupar lugar estratégico na política educacional para o ensino superior, sendo tratada pelos organismos internacionais como uma possibilidade de expansão do acesso ao ensino superior, com o objetivo de solucionar os problemas educacionais (OLIVEIRA, 2008). Isso trouxe novas relações para o trabalho docente nas universidades públicas, uma vez que as tecnologias estão sendo posicionadas no lugar dos sujeitos para aumentar a produtividade e racionalizar os gastos, fazendo com que professores das universidades assumam novas responsabilidades, intensificando o trabalho dos mesmos. Portanto, as políticas de educação superior do Estado capitalista nos anos do neoliberalismo da Terceira Via buscam otimizar os gastos, com aumento da produtividade docente.

Dessa maneira, o mercado de trabalho é reorganizado e o processo de intensificação, precarização e novas formas de exploração do trabalho docente é evidenciado.

\section{A configuração do Sistema UAB no processo de expansão da educação superior}

A UAB, instituída por meio do Decreto № 5.800/06, concerne em um sistema integrado por universidades públicas, que disponibilizam cursos de nível superior, por meio da EaD, para a população que possui dificuldade de acesso à formação universitária, sendo que os professores que atuam na educação básica têm prioridade de formação, seguidos dos dirigentes, gestores e trabalhadores em educação. A EaD foi o principal meio de expansão do ensino superior nos últimos anos.

O sistema UAB começou a se concretizar a partir da promulgação do Decreto $\mathrm{n}^{0}$ 5.622, de 19 de Janeiro de 2005, que regulamenta o artigo 80 da LDB 
no 9.394/96, dando ordenamento legal à $\mathrm{EaD}$ e estabelecendo diretrizes para a oferta de cursos na educação básica e superior, bem como na pós-graduação. Assim, experiências a distância no ensino superior, realizadas anteriormente a partir de consórcios estabelecidos entre universidades públicas, foram aprofundadas e deram origem à UAB.

Foi no âmbito do Ministério da Educação (MEC) que a UAB institucionalizou-se, sob responsabilidade da Diretoria de Educação a Distância (DED), ligada à Coordenação de Aperfeiçoamento de Pessoal de Nível Superior (CAPES), em parceria com a Secretaria de Educação a Distância (SEED) do MEC, a Associação Nacional dos Dirigentes das Instituições Federais de Ensino Superior (ANDIFES) e Empresas Estatais.

A UAB, especificamente, foi regulamentada pelo Decreto ํㅜ 5.800 , de 8 de junho de 2006, com a finalidade de expandir e interiorizar cursos e programas de educação superior, constituindo-se como um sistema nacional público de formação de professores a distância. Assim, apresenta cinco eixos fundamentais, que sinalizam para a expansão e consolidação de uma nova política de formação de professores no país. São eles:

- Expansão pública da educação superior, considerando os processos de democratização e acesso;

- Aperfeiçoamento dos processos de gestão das instituições de ensino superior, possibilitando sua expansão em consonância com as propostas educacionais dos estados e municípios;

- Avaliação da educação superior a distância tendo por base os processos de flexibilização e regulação implantados pelo MEC;

- Estímulo à investigação em educação superior a distância no País;

- Financiamento dos processos de implantação, execução e formação de recursos humanos em educação superior a distância. (BRASIL, 2006)

A Lei oㅜ 11.502, de 11 de julho de 2007, modifica as competências e a estrutura organizacional da CAPES, que passou a ser denominada "nova" CAPES, e, com isso, assume a função de coordenar ações direcionadas à formação inicial e continuada dos professores (DOURADO, 2008).

Em 2 de abril desse mesmo ano, a Portaria MEC № 318, transfere à CAPES a operacionalização da UAB, cabendo a SEED fornecer todos os dados, as informações e os recursos materiais e humanos necessários à CAPES. 
Nesse sentido, a UAB passou a ser um dos principais meios das políticas de expansão de matrículas na educação superior, bem como passou a representar um sistema nacional de EaD, consolidando um novo modelo de educação.

Nesse contexto, novos sujeitos passam a integrar o processo ensinoaprendizagem: professores das universidades públicas e tutores. Em contrapartida, recebem uma bolsa de estudo e pesquisa concedida pela CAPES, pagas pelo Fundo Nacional de Desenvolvimento da Educação (FNDE). Tal política coaduna-se com a política de Reestruturação e Expansão das Universidades Federais (REUNI), já que ambos se inserem na lógica de ampliar o acesso à educação superior pública, ampliando o número de alunos por professor.

A remuneração dos profissionais que atuam na UAB (coordenadores, professores e tutores) diferencia-se de acordo com a função exercida por cada um, não sendo cumulativas para aqueles que exerçam mais de uma função.

Os coordenadores-adjuntos, os coordenadores de curso, assim como os coordenadores de tutoria e os professores-pesquisadores, são professores ou pesquisadores designados/indicados pelas instituições públicas de ensino superior vinculadas à $U A B$, e todos, além de outras funções, desenvolvem projetos de pesquisas relacionados aos cursos. Enquanto o coordenador-adjunto atua nas atividades de coordenação e no apoio aos polos presenciais, o coordenador de curso atua mais diretamente na coordenação do curso. Já o coordenador de tutoria coordena os tutores e o professor-pesquisador desenvolve atividades típicas de ensino.

Diferentemente dos coordenadores e dos professores, o tutor é um profissional selecionado pelas instituições de ensino superior, sendo sua principal atribuição mediar a comunicação de conteúdos entre professores e estudantes. Nos processos seletivos de tutores cabe a cada instituição especificar as atividades a serem desenvolvidas por esses profissionais, conforme as especificidades das áreas e dos cursos. Já o coordenador de polo é um professor da rede pública selecionado para responder pela coordenação do polo de apoio presencial.

Para que os cursos a distância sejam oferecidos, a UAB estabelece parcerias com universidades públicas e secretarias de estados e municípios que se interessam em participar dos programas. Assim, é firmado um convênio sem a 
qual o curso não se realiza; estados e municípios assumem a responsabilidade de manterem os polos de apoio presencial.

Nos municípios participantes são criados polos presenciais, para que os alunos entrem em contato com tutores e com os professores formadores, vinculados às instituições federais, e tenham acesso a biblioteca e laboratórios de informática, biologia, química e física.

A adesão das instituições públicas de ensino superior e dos polos de apoio presencial - mantidos pelos governos estaduais e municipais - ao Sistema UAB necessita ser realizada no âmbito dos Fóruns Estaduais Permanentes de Apoio à Formação Docente, que, através de reuniões periódicas, autorizam ou não os pedidos de abertura de novos pólos, feitos à DDE.

O papel da UAB é articular, entre as instituições superiores e os governos estaduais e municipais, o atendimento de demandas locais de educação superior. Por isso, as instituições superiores participantes necessitam, obrigatoriamente, realizar atividades presencias na sede da instituição ou em polos de apoio presencial, que, de acordo com o Decreto ํㅜ 5.800/06, caracteriza-se "[...] como unidade operacional para o desenvolvimento descentralizado de atividades pedagógicas e administrativas relativas aos cursos e programas ofertados a distância pelas instituições públicas de ensino superior" (BRASIL, 2006).

Desse modo, a UAB trata-se de um sistema e não de uma universidade, já que é formada por várias instituições públicas de ensino superior e não se baseia no tripé ensino, pesquisa e extensão. Portanto, difere-se dos projetos das Universidades Abertas dos países centrais, por não se configurar como uma universidade e por funcionar como um sistema que articula diferentes instituições da educação superior. Significa dizer que não há identidade própria, pois o sistema é multifacetado.

\section{A condição de trabalho docente na UAB: caso Pedagogia/UFJF}

Considerando a EaD um meio importante de expansão do ensino superior, será tratado, mais especificamente, da experiência do curso de Licenciatura em Pedagogia a distância da UFJF, vinculado ao Sistema UAB, tendo como foco de análise o trabalho docente na UAB.

Convém esclarecer que no âmbito da UFJF, os cursos a distância 
encontram-se lotados nas unidades acadêmicas distribuídas de acordo com o campo de saber, sendo que a maioria desses cursos contam com seu correspondente no presencial. Em algumas Instituições Federais de Educação Superior, os cursos a distância ficam concentrados no Centro de Educação a Distância (CEAD), um órgão que passa a ter o peso de uma unidade acadêmica.

De acordo com a Resolução oㅡ 02, de 26 de março de 2010, o CEAD da UFJF - antigo Núcleo de Educação a Distância (NEAD) existente desde 2005 -, a partir de março de 2010 fica institucionalizado como um órgão suplementar da UFJF, vinculado à Reitoria, tendo como responsabilidade coordenar, supervisionar e apoiar as atividades relacionadas a EaD, que fazem parte do sistema UAB.

A formação e capacitação de professores da educação básica são prioridades da $U A B$, por isso, oferece cursos de licenciatura e de formação em serviço (aperfeiçoamento e especialização). No entanto, também disponibiliza cursos superiores em outras áreas do saber.

$O$ curso de Licenciatura em Pedagogia a distância, vinculado à Faculdade de Educação (FACED) da UFJF e ao Sistema UAB, tem como objetivo formar professores para a educação infantil e anos iniciais do ensino fundamental, ampliando o acesso à educação superior pública, já que atinge diferentes regiões de Minas Gerais, principalmente aquelas em que há dificuldade de acesso pelos professores em exercício a cursos presenciais. Desse modo, o curso de Pedagogia/UAB não substitui ou sobrepõe ao curso presencial, mas configura-se como um mecanismo de ampliação do acesso à educação superior pública, tendo como alunos profissionais em exercício, inseridos na educação básica.

De acordo com o Projeto Político Pedagógico (PPP) do curso, a Pedagogia/UAB da UFJF teve início em 2007, com 350 vagas disponíveis. Nessa primeira fase do curso, denominada UAB I, foram contemplados 7 polos, com 50 vagas destinadas para cada um. Dando continuidade a oferta do curso, em 2009 iniciou-se a turma da UAB II, com 400 vagas; em 2011, a UAB III, com 250 vagas; e no segundo semestre de 2012, a UAB IV, com 250 vagas.

Em 2013, o curso possuía aproximadamente 505 alunos, distribuídos, principalmente, entre as turmas da UAB III e IV, sendo que das primeiras turmas, UAB I e UAB II, em torno de 170 alunos e de 130 alunos, respectivamente, concluíram o curso. As turmas em andamento contam com um total de 18 professores responsáveis pelas disciplinas (entre efetivos, substitutos e 
convidados), além dos professores vinculados à coordenação; bem como 62 tutores a distância, responsáveis por ministrarem as atividades no Ambiente Virtual da Aprendizagem (AVA) da Plataforma Moodle.

Além disso, ainda fazem parte do curso os tutores presenciais, vinculados aos polos atendidos. Esses sujeitos têm a função de auxiliar os alunos na utilização da Plataforma Moodle e trabalham junto com o coordenador do polo.

Ainda de acordo o PPP curso, o quadro docente da Pedagogia/UAB é composto por: professores gestores-orientadores, que assumem a docência em sua área de atuação e pesquisa, sendo professores da UFJF (ativos, substitutos, aposentados ou convidados); tutores, licenciados em diferentes áreas que atuam diretamente com os alunos no AVA a partir de uma determinada disciplina; equipe de coordenação, formada por professores e pesquisadores efetivos da UFJF, que se revezam na gestão da coordenação geral.

Segundo dados disponíveis na página eletrônica da Pedagogia/UAB da UFJF', a grade curricular do curso é estruturada por disciplinas ordenadas nos seguintes eixos: (i) eixo de educação infantil e anos iniciais do ensino fundamental; (ii) eixo de conhecimentos pedagógicos; (iii) eixo de integração. Verifica-se que há distinções entre a grade do curso presencial e do curso a distância. Os eixos marcam bem essa diferença. Enquanto no curso a distância encontra-se os eixos supracitados, no presencial predomina os seguintes eixos: (i) eixo de fundamentos; (ii) eixo de gestão educacional; (iii) eixo de saberes escolares; (iv) eixo transversal ${ }^{4}$.

$A$ vinculação dos docentes às disciplinas segue a mesma dinâmica do curso presencial, ou seja, obedece a área de formação e/ou domínio epistemológico do professor frente a um campo de conhecimento tematizado no currículo.

Os tutores são selecionados por edital público para a respectiva disciplina ofertada em cada polo. A formação mínima exigida é a licenciatura na área temática ou em área afim. Além disso, segundo termos do Edital oํ 037/125 de seleção de tutor para o curso de Pedagogia/UAB da UFJF, é exigido às

\footnotetext{
${ }^{3}$ Disponível em: <http://www.ufff.br/uabpedagogia/ > Acesso em: 14 jan. 2015.

${ }^{4}$ Disponível em: <http://www.ufff.br/deptoeducacao/files/2008/07/Reestrutura\%C3\%A7\%C3\%A3oCurricular-Pedagogia.pdf $>$ Acesso em: 23 ago. 2016.

${ }^{5}$ Disponível em: <http://www.cead.ufff.br/media/editais/2012/edital37 pedagogia.pdf> Acesso em: 23 ago. 2016.
} 
seguintes condições: ter vínculo com o setor público durante o período de atuação na tutoria; ser aluno de Programa de Pós-Graduação; ou ser profissional vinculado à Instituição de Ensino Superior de origem da tutoria.

$\mathrm{Na}$ pesquisa desenvolvida, trabalhou-se com dados do curso de Pedagogia/UAB da UFJF do segundo semestre de 2007 ao segundo semestre de 2012, o que abarcou 8 semestres da UAB I e a mesma quantidade da UAB II; 3 semestres da UAB III; e 1 semestre da UAB IV. Com isso, tem-se um total de 20 semestres. Nesse período, o curso contou com a atuação de 56 professores: 26 professores efetivos; 6 professores aposentados; 16 professores substitutos (sendo que 4 destes encerraram e continuaram atuando sem vínculo); 7 professores convidados sem vínculo trabalhista com a UFJF; e 1 Técnico Administrativo em Educação (TAE) exercendo a função de docente do curso.

Tendo em vista que o presente estudo objetivou analisar a nova configuração do trabalho docente na $\mathrm{UAB}$, a partir da figura do professor, dos 26 professores efetivos que atuaram no curso, 23 foram convidados para

responderem um questionário eletrônico com questões abertas e fechadas.

Optou-se pelos professores efetivos por considerar que os aposentados que atuam na UAB se encontram em outra condição institucional e de vida, e que os professores substitutos estão inseridos em outra dinâmica profissional (em geral são professores da educação básica). Dos 26 professores efetivos, 3 não foram convidados para responder o questionário pelos seguintes motivos: um deles se vincula a presente pesquisa na condição de orientador; outro por ter se aposentado recentemente e o terceiro por não pertencer mais ao quadro da UFJF.

Todos os professores convidados receberam o Termo de Consentimento Livre e Esclarecido, assim como o link do questionário via e-mail, com questões abertas e fechadas, para que pudessem respondê-lo de forma online. Dos 23 questionários enviados, obtive-se o retorno de 18, somente 5 professores não responderam o questionário.

Vários aspectos foram abordados no questionário em relação ao trabalho do professor na $U A B$, dentre eles: tempo de atuação no ensino superior presencial e a distância; experiência com ensino a distância ; inserção docente na UAB; motivo de vinculação ao curso de Pedagogia/UAB ; bolsa concedida pela CAPES e a adesão dos professores; condição do trabalho docente na UAB; rotina de trabalho com a inserção na UAB; quantidade de turma e alunos; 
horas de trabalho em ensino, pesquisa e extensão; realização de atividades do ensino a distância em casa; utilização do tempo livre e de lazer para realização de atividades da UAB; contato e relação com os tutores; condição assumida pelo tutor; contato com o tutor e implicação para o trabalho.

As análises dos dados obtidos a partir dos questionários aplicados aos professores compõem a reflexão apresentada nas considerações finais a seguir, visto que este trabalho, por se tratar de um artigo, não comporta a análise detalhada de todas as questões, conforme foi feito na dissertação 6 .

\section{Considerações finais}

$O$ presente estudo buscou analisar o trabalho docente no âmbito do Sistema UAB, com foco no curso de Pedagogia/UAB da UFJF, tendo o materialismo histórico como método de análise.

No decorrer da pesquisa realizada, foi possível verificar que a política de expansão da educação superior brasileira, que teve início nos anos de 1990 e foi aprofundada nos governos posteriores, não é neutra; está carregada de valores, concepções e intencionalidades, propostos pelo projeto político neoliberal da Terceira Via.

As estratégias para o delineamento do Estado e das políticas públicas nesse contexto, especificamente em relação à educação, envolveram a difusão de um novo senso comum acerca dos direitos sociais e das relações humanas referenciado no projeto hegemônico de poder.

Uma das características da configuração do Estado, verificada na teoria e prática social concreta, é o predomínio do modelo gerencial como referência para ordenar as políticas e as responsabilidades constitucionais do Estado em relação aos direitos de educação. Verificou-se também que as TIC foram introduzidas para alavancar certas ações estatais, principalmente na política educacional que, em nome do direito social à educação, vem produzindo consequências ainda não percebidas no plano imediato da vida.

As TIC nesse campo, mais do que um processo natural, foram convertidas sob a lógica instrumental do modelo gerencial de Estado. Verificou-se que isso

\footnotetext{
6 Disponível em: <http://www.ufff.br/ppge/files/2013/09/Disserta\%C3\%A7\%C3\%A3o-Final.pdf> Acesso em: 07 fev. 2017.
} 
significou a aceitação social de que a forma pragmática pode e deve predominar sobre o conteúdo social. Isto é, tomam-se os resultados imediatos sem considerar as implicações de longo prazo.

Compartilhando responsabilidades com os estados e municípios "parceiros", efetuando o pagamento de pessoal por meio de bolsas e intensificando e explorando o trabalho de professores, e porque não dizer, dos tutores, o bloco no poder criou mecanismo, talvez, sem precedentes em nossa história, qual seja: ampliou o direito ao acesso à educação superior às custas da exploração do trabalho de professores e tutores. Dessa forma, sem alterar substantivamente os investimentos públicos na educação superior, o bloco no poder acomoda as tensões e orienta a base da coesão social na educação e, ainda, consegue legitimar o modelo como válido socialmente.

Nesse sentido, as TIC, consideradas pelos professores um avanço do conhecimento que abre novas fronteiras para o trabalho, converte-se para o bloco no poder e seu modelo de Estado gerencial como um novo meio para o aumento da produtividade do trabalho com a racionalização (leia-se: economia) de gastos, com bons resultados finais. O caso do trabalho docente do curso de Pedagogia/UAB da UFJF investigado neste estudo exemplifica o que isso significa na prática concreta.

Se antes, a intensificação, a precarização e a terceirização do trabalho (contratação dos tutores que não possuem vínculo institucional trabalhista) eram marcas do setor privado, o caso da Pedagogia/UAB exemplifica que tal processo se tornou realidade no setor público.

Acredita-se que a afirmação do direito social à educação não pode ser operada na negação do direito social ao trabalho digno. Isso tende a invalidar as possíveis conquistas sob o ponto de vista econômico-gerencial, em função dos efeitos negativos de médio (qualidade da formação dos discentes em decorrência do estranhamento do trabalho) e de longo prazo (custos do adoecimento docente). Usando uma linguagem direta: questiona-se a validade de um modelo em que os professores e tutores arcam com os custos da expansão do ensino superior.

Com efeito, acredita-se que o modelo em curso da Pedagogia/UAB, apesar de suas características singulares no contexto mais amplo da EaD, precisa ser avaliado sobre o ângulo das formas não aparentes que o constitui e dinamiza.

TrabalhoNecessario - www.uff.br/trabalhonecessario; Ano 15, № 26/2017 
Isso significa que: se é importante considerar que pessoas estão obtendo um título acadêmico, inserindo-se sob novas condições no mercado de trabalho e ampliando seus horizontes de vida, é importante considerar também quais são os custos pessoais da forma com que essa modalidade se desenvolve.

Não se trata de questionar a potencialidade da EaD, mas sim inquirir se as bases sociais e fundamentos políticos, ideológicos e financeiros com as quais essa modalidade se desenvolve na atualidade são adequados quando pensa-se a condição do ser humano que trabalha.

Nesse sentido, considera-se que a Faculdade de Educação da UFJF se encontra diante de um desafio: analisar as implicações políticas e sociais sobre o trabalho docente no âmbito do curso de Pedagogia/UAB e se posicionar politicamente sobre a condição humana do trabalhador docente e sobre o direito social do trabalho digno.

Novos estudos precisam ser realizados sobre essa temática para ampliar a apreensão do fenômeno em questão e, assim, permitir a construção de posições críticas, tendo como referência a condição de vida/trabalho dos professores.

\section{Referências}

ANTUNES, Ricardo. Adeus ao trabalho?: ensaios sobre as metamorfoses e a centralidade do mundo do trabalho. 4. ed. São Paulo: Cortez. 1997.

BOMFIM, Maria Inês do Rego Monteiro. Trabalho docente na escola pública brasileira: as finalidades humanas em risco. In: CIAVATTA, M.; REIS, R. R. (orgs.). A pesquisa histórica em trabalho e educação. Brasília: Liber Livro Editora, 2010. p. 89-111.

Trabalho docente, classe e ideologia: o Ensino Médio e a modernização conservadora no Brasil. Tese (Doutorado em Educação) - Programa de PósGraduação em Educação, Universidade Federal Fluminense, Niterói, 2008.

BRASIL, Decreto ํㅜ 6.755, de 29 de janeiro de 2009. Institui a Política Nacional de Formação de Profissionais do Magistério da Educação Básica, disciplina a atuação da Coordenação de Aperfeiçoamento de Pessoal de Nível Superior CAPES no fomento a programas de formação inicial e continuada, e dá outras providências. Disponível em: <http://www.planalto.gov.br/ccivil 03/ ato20072010/2009/Decreto/D6755.htm > Acesso em: 13 ago 2016.

$\overline{\text { Universidade }}$

Decreto $n^{\circ}$ 5.800, de 8 de junho de 2006. Dispõe sobre o Sistema
Aberta
do
Brasil- UAB.
Disponível

em: 
$<$ http://www.planalto.gov.br/ccivil 03/ ato2004-2006/2006/decreto/d5800.htm> Acesso em: 10 jun. 2016.

Decreto $n^{\circ}$ 5.622, de 19 de dezembro de 2005. Regulamenta o artigo 80 da Lei no 9.394, de 20 de dezembro de 1996, que estabelece as diretrizes e bases da educação nacional. Disponível em: <http://www.planalto.gov.br/ccivil 03/ Ato2004-2006/2005/decreto/D5622.htm> Acesso em: 15 jun. 2016.

. Lei no 11.502, de 11 de julho de 2007. Modifica as competências e a estrutura organizacional da fundação Coordenação de Aperfeiçoamento de Pessoal de Nível Superior - CAPES, de que trata a Lei no 8.405, de 9 de janeiro de 1992; e altera as Leis no 8.405, de 9 de janeiro de 1992, e no 11.273, de 6 de fevereiro de 2006, que autoriza a concessão de bolsas de estudo e de pesquisa a participantes de programas de formação inicial e continuada de professores para a educação básica. Disponível em: <http://www.leidireto.com.br/lei-11502.html> Acesso em: 10 ago. 2016.

Bases . Lei no 9.394, de 20 de dezembro de 1996. Estabelece as Diretrizes e <http://www.planalto.gov.br/ccivil 03/leis/19394.htm> Acesso em: 5 fev. 2016.

. Portaria n 18, de 2 de abril de 2009. Transfere à Coordenação de Aperfeiçoamento de Pessoal de Nível Superior - CAPES a operacionalização do Sistema Universidade Aberta do Brasil - UAB. Disponível em:

$<$ http://www.uab.capes.gov.br/images/stories/downloads/legislacao/Portaria318 2 Abr09 UABparaCAPES.pdf > Acesso em: 10 set. 2016.

CEAD. Edital no 037, de 2012. Disponível em:

$<$ http://www.cead.ufff.br/media/editais/2012/edital37 pedagogia.pdf> Acesso em: 14 mar. 2016.

CONSELHO SUPERIOR UFJF. Resolução no 02, de 26 de março de 2010. Disponível em: <http://www.ufjf.br/propg/files/2009/11/Resolu\%C3\%A7\%C3\%A3o02.2010-CONSU.pdf> Acesso em: 17 abr. 2016.

DOURADO, Luiz Fernandes. Políticas e gestão da educação superior a distância: novos marcos regulatórios. Educação \& Sociedade, Campinas, v. 29, n. 104, p.891-917, out. 2008. Disponível em: <http://www.scielo.br/pdf/es/v29n104/a1229104> Acesso em: 26 de nov. 2016.

ENGELS, Friedrich. Sobre o papel do trabalho na transformação do macaco em homem, 1876. In: ANTUNES, R. A dialética do trabalho: escritos de Marx e Engles. São Paulo: Expressão Popular, 2004. p. 11-28.

FRIGOTTO, Gaudêncio. A polissemia da categoria trabalho e a batalha de ideias nas sociedades de classe. Revista Brasileira de Educação, Campinas, v. 14, n. 40, jan./abr. 2009. Disponível em: $<$ http://www.scielo.br/pdf/rbedu/v14n40/v14n40a14.pdf> Acesso em: 15 jan. 2016. 
. Educação e a crise do capitalismo real. 5. ed. São Paulo: Cortez, 2003.

GIDDENS, Antony. A terceira via: reflexões sobre o impasse político atual e o futuro da social-democracia. 4. ed. Rio de Janeiro: Record, 2001.

GRAMSCI, Antonio. Cadernos do cárcere. Volume 3. Maquiavel. Notas sobre o Estado e a Política. Tradução de Carlos Nelson Coutinho, Luiz Sérgio Henriques e Marco Aurélio Nogueira. 4. ed. Rio de Janeiro: Civilização Brasileira, 2011.

HOBSBAWM, Eric. Era dos extremos: o breve século XX: 1914-1991. Tradução de Marcos Santarrita. 2. ed. São Paulo: Companhia da Letras, 1995.

KOSIK, Karel. Dialética do concreto. 2. ed. Rio de Janeiro: Paz e Terra, 1976.

MARTINS, André Silva. O Estado educador: notas para a reflexão. In: ANDRADE, J.; PAIVA, L. G. As políticas para a educação no Brasil contemporâneo: limites e contradições. Juiz de Fora: UFJF, 2011. p.72-89.

MARX, Karl. Processo de trabalho e processo de valorização, 1983. In: ANTUNES, R. A dialética do trabalho: escritos de Marx e Engles. São Paulo: Expressão Popular, 2004. p. 29-56.

. Trabalho Produtivo e Trabalho Improdutivo, 1978. In: ANTUNES, R. A dialética do trabalho: escritos de Marx e Engles. São Paulo: Expressão Popular, 2004. p. 125-140.

Salário, Preço e Lucro, 1950. In: ANTUNES, R. A dialética do trabalho: escritos de Marx e Engles. São Paulo: Expressão Popular, 2004. p. 57-100.

OLIVEIRA, Daniela Motta de. A formação de professores a distância para a nova sociabilidade: análise do "PROJETO VEREDAS" de Minas Gerais. Tese (Doutorado em Educação) - Programa de Pós-Graduação em Educação, Universidade Federal Fluminense, Rio de Janeiro, 2008.

OSÓRIO, Mara Rejane Vieira; GARCIA, Maria Manuela Alves. Universidade Aberta do Brasil (UAB): (re)modelando o território da formação de professores. Cadernos de Educação, Pelotas, p. 119-149, jan./abr. 2011. Disponível em:

$<$ http://www.ufpel.edu.br/fae/caduc/downloads/n38/05.pdf.> Acesso em: 12 out 2016.

POULANTZAS, Nicos. O Estado, o poder, o socialismo. São Paulo: Paz e Terra, 2000.

TEODORO, António. O fim do isolacionismo da participação de Portugal no Plano Marshall ao Projecto Regional do Mediterrâneo. 2000. Disponível em: $<$ http://revistas.ulusofona.pt/index.php/rhumanidades/article/view/1330/1083> Acesso em: 27 abr 2016.

TREIN, Daiana; CHAGAS, Wagner. Universidade(?) Aberta(?) do Brasil: uma análise preliminar contextual e conceitual. In: CONGRESSO INTERNACIONAL 
DE EDUCAÇÃO, VI, 2009, Porto Alegre. Educação e Tecnologias: sujeitos (des)conectados. Porto Alegre, 2009.

UNIVERSIDADE FEDERAL DE JUIZ DE FORA. Projeto Político Pedagógico Pedagogia UAB. Juiz de Fora, 2012.

Recebido em: 08 de fevereiro de 2017 Aprovado em: 05 de abril de 2017 Pubicado em: 4 de junho de 2017 